\section{A cross sectional study of alcohol consumption and risk}

\section{factors}

\author{
R Dinesh Kumar ${ }^{1}$, J Kalaiselvi ${ }^{2}$ and Siva S $^{2 *}$ \\ ${ }^{1}$ Assistant professor, Department of pharmacy practice, The Erode College of Pharmacy, Erode, Tamil \\ Nadu, India \\ 2Doctor of Pharmacy, The Erode College of Pharmacy, Erode, Tamil Nadu, India
}

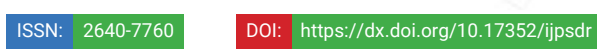

Received: 14 July, 2020

Accepted: 22 September, 2020

Published: 23 September, 2020

*Corresponding author: Siva S, Doctor of Pharmacy, The Erode College of Pharmacy, Erode, Tamil Nadu, India, E-mail: adamsivagi@gmail.com

Keywords: Alcohol; Hypertension; Diabetes; Sleep apnea; Prospective study

https://www.peertechz.com

Check for updates

\begin{abstract}
Introduction : Alcohol consumption is an important contributor to the global burden of different disease such as stroke, sleep apnea, pancreatitis, diabetes mellitus, CAD and so on. Urban populations are having greater risk of getting the alcohol induced disease.
\end{abstract}

Objective: A cross sectional study of alcohol consumption associated with risk of different disease. To inspect the correlation between alcohol intake and risk on different disease in men and women based on their age group and which leads to other diseased condition.

Methods: A descriptive cross sectional survey was conducted involving 100 adults at 18 years of age or above who were recruited with cluster random sampling. Demographic data and risk factors were determined by taking history, physical examination and laboratory test.

Result: Studies shows that alcohol consumption increases the risk factor for those diseased condition i.e., it increases the risk on stroke, hypertension, coronary artery disease, Type 2 diabetes, life style. Results from our quantitative meta analysis showed that drinkers with average intake of less than $30 \mathrm{~g} /$ day and no episodic heavy drinking had a lowest risk on above complication.

Discussion: Comparing to the present study with the former research the prevalence of a number of risk factors can be seen in the present research. We found out different statistical pattern.

Conclusion: These findings indicate that alcohol consumption from mild to moderate intake is a risk factor for different diseases.

\section{Introduction}

Alcohol consumption is an important contributor to the global burden of disease, responsible for $4 \%$ of disabilityadjusted life years $[1,2]$. While disease burden is somewhat lower in low income geographic regions where abstinence is common, there is concern that urbanization is associated with increased alcohol use [3-5].

OSA is thought to be more common among people who consume alcohol, possibly because alcohol increases upper airway collapsibility [6-8] and also because alcohol intake can contribute to a higher body mass index. However, evidence on the effect of alcohol consumption on the risk of OSA remains mixed, with some studies reporting an increased risk in those who consume alcohol [9-11].
It is becoming increasingly clear that alcohol consumption is a factor of importance for the risk of type 2 diabetes. Data from epidemiological studies suggest a protective effect of moderate alcohol consumption [12].

In addition, long-term heavy alcohol consumption can have toxic effects on the heart and cause cardiomyopathy and, consequently, increase the risk of HF. In contrast, low to moderate consumption of alcohol can have an overall cardiovascular benefit and may reduce HF risk [13]. Because of the risks associated with high alcohol intake, clinical guidelines generally do not recommend alcohol consumption; rather, they suggest that other lifestyle features be emphasized. For example, a recent review of alcohol and CHD stated, "We have other means of lowering cardiovascular risk that are safe and proven [14]. 
Diverse risk factors, such as sugar-sweetened beverages, smoking and coffee consumption, have been investigated to be associated with the incidence of type 2 diabetes. A number of recent prospective studies have also attracted attention to the role of alcohol consumption in the development of type 2 diabetes [15,16]. How alcohol consumption affects the risks of health conditions has been well characterized. At lower levels of consumption, studies suggest alcohol consumption is associated with both increased health risks for some conditions (e.g. cancers, liver cirrhosis) and decreased for others (e.g. ischemic heart disease, ischemic stroke). It also clear that patterns of drinking, as well as volume, play an important role in both the disease burden and health benefits associated with drinking [17].

We have previously shown that moderate alcohol consumption lowers the risk of incident type 2 diabetes [18]. However, since alcohol consumption has been associated with increased triglycerides [19], body weight [20], and blood pressure $[21,22]$ it may have adverse consequences for individuals with diabetes. In this systematic review we examined the relationship between alcohol consumption and long-term complications of type 2 diabetes. Consequently, alcohol consumption and raised blood pressure are among the top five risk factors responsible for the growing global non-communicable diseases (NCD) burden [23]. It is well accepted that heavy alcohol consumption has been linked to an increased risk of ischemic stroke [24] and hemorrhagic stroke $[25,26]$. However, some studies of moderate alcohol and stroke reported a protective effect of alcohol at these doses [27-29] while others have found that moderate consumption increases the overall risk [30].

The most common cardiac arrhythmia, is accompanied with a 4- to 5-fold increased risk for stroke, tripling of the risk for heart failure, doubling of the risk for dementia, and $40 \%$ to $90 \%$ increase in the risk for all-cause mortality [31]. High alcohol consumption also has been associated with an increased AF risk. However, few studies have detected an association between light to moderate alcohol drinking and AF [32-35]. Recently, it has been hypothesized that not only episodic but also habitual heavy alcohol consumption is associated with the risk of $\mathrm{AF}[36]$.

Perhaps because acute alcohol intoxication increases the risk of aspiration and pulmonary infection, while chronic alcohol ingestion disturbs both immunologic and non immunologic host defense mechanisms within the airway, resulting in alveolar macrophage immune dysregulation and alveolar epithelial barrier dysfunction [37]. Alcohol consumption is considered one of the major causative agents for pancreatitis ; after gallstones, alcohol is the second major leading cause of $\mathrm{AP}$ and the most common cause of $\mathrm{CP}$ [38].

\section{Methods}

\section{Study selection}

We identified potentially relevant articles regardless of language by a computerized search of the Pub Med database from inception. We used the search terms 'alcohol consumption', 'alcohol drinking', or 'alcohol intake' combined with 'complications" and 'prospective study'. The reference lists of pertinent articles were reviewed to identify additional studies. Eligibility criteria for inclusion in the present study were: (i) The study was prospective (ii) The exposure was alcohol consumption; (iii) The outcome on complications on alcohol incidence (hospitalization) and/or mortality; (iv) The population was free from complications of alcoholism.

\section{Type of participants}

All studies of adults aged 18 years and over were eligible for inclusion in this review.

\section{Type of exposure}

We included all studies that had assessed alcohol consumption, either by self-report or a proxy such as clinical records, defined either as drinking level (low, moderate, heavy, alcohol abuse, alcoholism) or as frequency (grams per day).

\section{Study design}

All the primary comparative observational studies were included (longitudinal/cohort, case control, cross sectional).

\section{Inclusion and exclusion criteria}

To be included in our meta-analysis, a published study had to meet the following criteria: (1) had to be an original research study (not a review); (2) cohort or case control study in which medically confirmed on complication on alcohol (i.e., not self reported endpoint); (3) reporting data on alcohol consumption and complications (4) having three or more alcohol drinking exposure groups

\section{Data extraction}

All data were independently abstracted by means of a standardized protocol. Study characteristics recorded were as follows: title, lead author name, year, and source of publication, country of origin, study design (cohort study or case-control study), characteristics of the study population (sample size; sampling methods; and distribution of age, average age at baseline, sex, and ethnicity) measures of outcome and exposure (the number of cases at each exposure level, the total population at risk at each exposure level), duration of followup (for prospective cohort studies).

\section{Standardization of alcohol consumption}

Where consumption was reported in drinks and not grams, the gram pure alcohol equivalent described in the article was used as a conversion factor if stated, and if not, conversion from standard drinks was based on geography. For all other countries without clear standard drink specifications 12 grams pure alcohol was used. For those studies that did not report measures of association separately by sex, the estimates were used for men as well as women. Information on alcohol consumption was extracted. When ranges of alcohol consumption were given, the midpoint was taken. In cases 
where no upper bound for the highest category was given, 3/4 of the length of the immediate previous category range was added to the lower bound and was used as the measure.

\section{Statistical analysis}

The data were collected and arranged at excel sheet of Microsoft excel version 13. Descriptive analysis was used to process the outcomes in tables and graphs.

\section{Result}

Alcohol consumption is one of the major cause for death. It also causes many other diseased condition which leads to death. Both men and women are almost equal in intake of alcohol at the period of 18 to 24 years of age. So the risk for the diseased condition are common for both. Women's are taking more alcohol than men so the risk will be more among them.

Alcoholism among the age group and time period is an important factor in influencing complication to diseased condition. It can be clearly understand from Tables 1,2 which shows percentage duration of drink and age group.

Risk factor for the alcoholism increases the diseased condition. It mainly includes hypertension, DM, CAD, Dyslipidemia, sleep apnea and so on. Table 3 shows the risk factors for the diseased condition.

Table 1: Percentage use of drinks among men and women.

\begin{tabular}{|c|c|c|}
\hline Type of drink & Men (\%) & Women (\%) \\
\hline All alcoholic drinks & 22.6 & 13.9 \\
\hline Wine & 1.2 & 3.4 \\
\hline Normal beer & 12.0 & 2.2 \\
\hline Strong beer & 1.9 & 0.2 \\
\hline Sprit & 5.4 & 5.3 \\
\hline alcopops & 1.4 & 2.0 \\
\hline
\end{tabular}

Table 2: Percentage showing duration of drink and age group.

\begin{tabular}{|c|c|c|c|c|c|c|c|c|}
\hline & \multicolumn{2}{|c|}{$\mathbf{1 8 - 2 9}$ years } & \multicolumn{2}{|c|}{$\mathbf{3 0 - 4 9}$ years } & \multicolumn{2}{|c|}{$\mathbf{5 0 - 6 9}$ years } & \multicolumn{2}{c|}{ Above 70 years } \\
\cline { 2 - 10 } & men & women & men & women & men & women & men & women \\
\hline 24 hours & $28 \%$ & $15 \%$ & $33 \%$ & $24 \%$ & $38 \%$ & $28 \%$ & $57 \%$ & $31 \%$ \\
\hline 1 day -1 week & $47 \%$ & $33 \%$ & $38 \%$ & $34 \%$ & $32 \%$ & $27 \%$ & $16 \%$ & $20 \%$ \\
\hline Over 1 week ago & $25 \%$ & $51 \%$ & $29 \%$ & $42 \%$ & $30 \%$ & $45 \%$ & $27 \%$ & $49 \%$ \\
\hline
\end{tabular}

Table 3: Percentage of risk factor among men and women.

\begin{tabular}{|c|c|c|}
\hline Risk factor & Men (\%) & Women (\%) \\
\hline Currently smoker & $45.3 \%$ & $34.2 \%$ \\
\hline Hypertension & $36.34 \%$ & $28.85 \%$ \\
\hline DM & $1.78 \%$ & $1.21 \%$ \\
\hline CAD & $12.1 \%$ & $7.3 \%$ \\
\hline Total cholesterol & $5.4 \%$ & $9.9 \%$ \\
\hline Obesity & $14.5 \%$ & $13.9 \%$ \\
\hline Sleep apnea & $1.3 \%$ & $0.3 \%$ \\
\hline
\end{tabular}

\section{Discussion}

Alcoholism is the epidemic of our time and set to remain the single most important disease in the world in the terms of mortality, morbidity, disability and economic loss until 2020. Alcoholism has been known by a variety of terms, including alcohol abuse and alcohol dependence. Today, it's referred to as alcohol use disorder. It occurs when you drink so much that your body eventually becomes dependent on or addicted to alcohol. When this happens, alcohol becomes the most important thing in your life. People with alcohol use disorder will continue to drink even when drinking causes negative consequences, like losing a job or destroying relationships with people they love. They may know that their alcohol use negatively affects their lives, but it's often not enough to make them stop drinking. Some people may drink alcohol to the point that it causes problems, but they're not physically dependent on alcohol. This used to be referred to as alcohol abuse.womens are comman among them. They are more in the field of alcohol use and risk will be more for them. This graphs and tables are obtained from the survey. It will provide the information about the drinking habit.

For primarily prevention purpose individuals with documented risk factors should actively pursue risk factor modifications to reduce the risk of future complication events. Lifestyle modifications with guidance and strong encouragement of the physician- led health care team can make a significant positive impact on future complications rate.

\section{Conclusion}

According to the prevalence of risk factor which $45.3 \%$ of men and $34.2 \%$ of women of the study population were currently smokers. $36.34 \%$ of men and $28.85 \%$ of women of the study population were currently hypertensive patients. $1.78 \%$ of men and $1.21 \%$ of women of the study population were currently DM. $5.4 \%$ of men and $9.9 \%$ of women of the study population were currently dyslipidemic. $14.5 \%$ of men and $13.9 \%$ of women of the study population were currently obese. The researches strongly recommended all population strategy of primary prevention of alcoholism to be designed and practiced. Managing the burden of risk factors can be prevented the following diseased condition and should assist managing the future conditions.

\section{References}

1. Ezzati M, Lopez AD, Rodgers A, Murray CJ (2004) Comparative Quantification of Health Risks Global and Regional Burden of Disease Attributable to Selected Major Risk Factors; World Health Organization: Geneva, Switzerland. Link: https://bit.ly/32Pbluk

2. Rehm J, Taylor B, Room R (2006) Global burden of disease from alcohol, illicit drugs and tobacco. Drug Alcohol Rev 25: 503-513. Link: https://bit.ly/2HnrSO3

3. Room R, Jernigan D, Carlini-Marlatt B, Gureje O, Mäkelä K, et al. (2002) Alcohol in Developing Societies: A Public Health Approach; Finnish Foundation for Alcohol Studies in collaboration with The World Health Organization: Helsinki, Finland 46. Link: https://bit.ly/2RKdoto

4. World Health Organisation (2004) Global Status Report on Alcohol; World Health Organisation: Geneva, Switzerland. 
5. Kilonzo GP, Hogan NM, Mbwambo JK, Mamuya B, Kilonzo K (2004) Pilot studies on patterns of consumption of nonindustrial alcohol beverages in selected sites, Dar es Salaam, Tanzania. In Moonshine Markets: Issues in Unrecorded Alcohol Beverage Production and Consumption; Haworth, A, Simpson, R, Eds.; Brunner-Routledge: New York, NY, USA.

6. Punjabi NM (2008) The epidemiology of adult obstructive sleep apnea. Proc Am Thorac Soc 5: 136e43. Link: https://bit.ly/3clpIPG

7. Franklin KA, Lindberg E (2015) Obstructive sleep apnea is a common disorde in the populationda review on the epidemiology of sleep apnea. J Thorac Dis 7: 1311-1322. Link: https://bit.ly/32TtJm5

8. Mitler MM, Dawson A, Henriksen SJ, Sobers M, Bloom FE, et al. (1988) Bedtime ethanol increases resistance of upper airways and produces sleep apneas in asymptomatic snorers. Alcohol Clin Exp Res 12: 801e5. Link: https://bit.ly/3hZ2ESQ

9. Baik I, Seo HS, Yoon D, Kim SH, Shin C (2015) Associations of sleep apnea, NRG1 polymorphisms, alcohol consumption, and cerebral white matter hyperintensities: analysis with genome-wide association data. Sleep 38: 1137 1143. Link: https://bit.ly/3cmEzEb

10. Poul JAS (1994) Self- assessed cognitive function in snorers and sleep apneics. Eur Neurol 34: 204e8. Link: https://bit.ly/3cp0nin

11. Sharma SK, Kumpawat S, Banga A, Goel A (2006) Prevalence and risk factors of obstructive sleep apnea syndrome in a population of Delhi, India. Chest 130. Link: https://bit.ly/3hLFRKO

12. Howard AA, Arnsten JH, Gourevitch MN (2004) Effect of alcohol consumption on diabetes mellitus: a systematic review. Ann Intern Med 140: 211-219. Link: https://bit.ly/35YjBu6

13. Lee WK, Regan TJ (2002) Alcoholic cardiomyopathy: is it dose-dependent? Congest Heart Fail 8: 303-306. Link: https://bit.ly/2FYwl9f

14. Lieber CS (2003) Alcohol and health: a drink a day won't keep the doctor away. Cleve Clin J Med 70: 945-946. Link: https://bit.ly/3hMzcza

15. Pietraszek A, Gregersen S, Hermansen K (2010) Alcohol and type 2 diabetes. A review. Nutr Metab Cardiovasc Dis 20: 366-375. Link: https://bit.ly/33R9Gnh

16. Seike N, Noda M, Kadowaki T (2008) Alcohol consumption and risk of type 2 diabetes mellitus in Japanese: a systematic review. Asia Pacific J Clin Nutri 17: 545-551. Link: https://bit.ly/3iR5vOI

17. Babor TF, Caetano R, Casswell S, Edwards G, Giesbrecht N, et al. (2010) Alcohol: no ordinary commodity. Research and public policy. New York: Oxford University Press. Link: https://bit.ly/2ZZSGu3

18. Koppes LLJ, Dekker JM, Hendriks HFJ, Bouter LM, Heine RJ (2005) Moderate alcohol consumption lowers the risk of type 2 diabetes-a meta-analysis of prospective observational studies. Diabetes Care 28: 719-725. Link: https://bit.ly/3iYwl2g

19. Rimm EB, Williams P, Fosher K, Criqui M, Stampfer MJ (1999) Moderate alcohol intake and lower risk of coronary heart disease: meta-analysis of effects on lipids and haemostatic factors. BMJ 319:1523-1528. Link: https://bit.ly/2ZXoDDq

20. Wannamethee SG, Shaper AG (2003) Alcohol, body weight, and weight gain in middle-aged men. Am J Clin Nutr 77: 1312-1317. Link: https://bit.ly/32PsyE0

21. Kato I, Kiyohara Y, Kubo M, Shinohara N, Nakayama K, et al. (2003) Insulinmediated effects of alcohol intake on serum lipid levels in a general population. The Hisayama Study. J Clin Epidemiol 56: 196-204. Link: https://bit.ly/33M5zJi
22. Thadhani R, Camargo CA, Stampfer MJ, Curhan GC, Willett WC, Rimm EB (2002) Prospective study of moderate alcohol consumption and risk of hypertension in young women. Arch Intern Med 162: 569-574. Link: https://bit.ly/3mlYouc

23. GBD 2015 Risk Factors Collaborators (2016) Global, regional, and nationa comparative risk assessment of 79 behavioural, environmental and occupational, and metabolic risks or clusters of risks, 1990-2015: a systematic analysis for the Global Burden of Disease Study 2015 Lancet 2016; 388: 1659724. Link: https://bit.ly/3mGNuFg

24. Caicoya M, Rodriguez T, Corrales C, Cuello R, Lasheras C (1999) Alcohol and stroke. A community case control study in Astrurias, Spain. J Clin Epidemio 52: 677-684. Link: https://bit.ly/3cIDwnT

25. Thrift A, Donnan G, McNeil J (1999) Heavy drinking, but not moderate or intermediate drinking, increases the risk of intracerebral hemorrhage. Epidemiol 10: 307-312. Link: https://bit.ly/2EsoZug

26. Donahue RP, Abbott RD, Reed DM, Yano K (1986) Alcohol and hemorrhagic stroke: the Honolulu Heart Program. JAMA 255: 2311-2314. Link: https://bit.ly/2RMgehJ

27. Jamrozik K, Broadhurst RJ, Anderson CS, Stewart-Wynne EG (1994) The role of lifestyle factors in the etiology of stroke: a population-based casecontrol study in Perth, Western Australia. Stroke 25: 51-59. Link: https://bit.ly/2HINWsm

28. Malarcher AM, Giles WH, Croft JB, Wozniak MA, Wityk RJ, et al. (2001) Alcoho intake, type of beverage, and the risk of cerebral infarction in young women. Stroke 32: 77-83. Link: https://bit.ly/3kEs8qg

29. Gill JS, Shipley MJ, Tsementzis SA, Hornby RS, Gill SK, et al. (1991) Alcohol consumption: a risk factor for hemorrhagic and nonhemorrhagic stroke. Am J Med 90: 489-497. Link: https://bit.ly/33PQ7Mo

30. Gorelick P, Rodin MB, Langenberg P, Hier DB, Costigan J (1989) Weekly alcohol consumption, cigarette smoking, and the risk of ischemic stroke: results of a case-control study at three urban medical centers in Chicago, Illinois. Neurology 39: 339-343. Link: https://bit.ly/2ZUsjWf

31. Benjamin EJ, Chen PS, Bild DE, Mascette AM, Albert CM, et al. (2009) Prevention of atrial fibrillation: report from a national heart,lung, and blood institute workshop. Circulation 119: 606-618. Link: https://bit.ly/3iTpU5U

32. Djousse L, Levy D, Benjamin EJ, Blease SJ, Russ A, et al. (2004) Longterm alcohol consumption and the risk of atrial fibrillation in the Framingham Study. Am J Cardiol 93: 710-713. Link: https://bit.ly/2RMS5rb

33. Frost L, Vestergaard P (2004) Alcohol and risk of atrial fibrillation or flutter: a cohort study. Arch Intern Med 164: 1993-1998. Link: https://bit.ly/35V54iH

34. Conen D, Tedrow UB, Cook NR, Moorthy MV, Buring JE, et al. (2008) Alcoho consumption and risk of incident atrial fibrillation in women. JAMA 300: 2489 2496. Link: https://bit.ly/2ZU18uQ

35. Liang Y, Mente A, Yusuf S, Gao P, Sleight P, et al. (2012) Alcohol consumption and the risk of incident atrial fibrillation among people with cardiovascular disease. CMAJ 184: E857-E866. Link: https://bit.ly/35Vf3EG

36. Balbao CE, de Paola AA, Fenelon G (2009) Effects of alcohol on atria fibrillation: myths and truths. Ther Adv Cardiovasc Dis 3: 53- 63. Link: https://bit.ly/35Yhnuz

37. Mehta A (2013) Pulmonary consequences of alcoholism: a critical review. OA Alcohol 1: 17. Link: https://bit.ly/3ckTb6P

38. Yadav D, Lowenfels A (2006) Trends in the epidemiology of the first attack of acute pancreatitis. A systematic review. Pancreas 33: 323-330. Link: https://bit.ly/3mHOpW4

Copyright: @ 2020 Kumar RD, et al. This is an open-access article distributed under the terms of the Creative Commons Attribution License, which permits unrestricted use distribution, and reproduction in any medium, provided the original author and source are credited.

Citation: Kumar RD, Kalaiselvi J, Siva S (2020) A cross sectional study of alcohol consumption and risk factors. Int J Pharm Sci Dev Res 6(1): $034-037$. 